\title{
Connective Eccentric Index of Circumcoronene Homologous Series of Benzenoid $\boldsymbol{H}_{k}$
}

\author{
Mohammad Reza Farahani \\ Department of Applied Mathematics of Iran University of Science and Technology (IUST), \\ Narmak, Tehran 16844, Iran \\ E-mail address: Mr_Farahani@Mathdep.iust.ac.ir , MrFarahani88@Gmail.com
}

\begin{abstract}
Let $G$ be a molecular graph, a topological index is a numeric quantity related to $G$ which is invariant under graph automorphisms. The eccentric connectivity index $\xi(G)$ is defined as $\xi(G)=$ $\sum_{v \in V(G)} d_{v} \times \varepsilon(v)$ where $d_{v}, \varepsilon(v)$ denote the degree of vertex $v$ in $G$ and the largest distance between $v$ and any other vertex $u$ of $G$. The connective eccentric index of graph $G$ is defined as $C^{\xi}(G)=$ $\sum_{v \in V(G)} d_{v} / \varepsilon(v)$. In the present paper we compute the connective eccentric index of Circumcoronene
\end{abstract} Homologous Series of Benzenoid $H_{k}(k \geq 1)$.

Keywords: Molecular graphs; Benzenoid; Connective eccentric index; Eccentric connectivity index

\section{INTRODUCTION}

In theoretical chemistry molecular structure descriptor or topological indices, are used to compute properties of chemical compounds. Throughout this paper, graph means simple connected graph [1-3]. Let $G$ be a molecular graph, the vertex and edge sets of a graph $G$ are denoted by $V(G)$ and $E(G)$, respectively. If $x, y \in V(G)$ then the distance $d(x, y)$ between $x$ and $y$ is defined as the length of a minimum path connecting $x$ and $y$.

In 1997, the Eccentric Connectivity index $\xi(G)$ of the molecular graph $G$ was proposed by Sharma, Goswami and Madan and is defined as [4]:

$$
\xi(G)=\sum_{v \in V(G)} d_{v} \times \varepsilon(v)
$$

where $d_{v}$ denotes the degree of the vertex $v$ in $G$ and $\varepsilon(v)$ denote the largest distance between $v$ and any other vertex $u$ of $G$. In other words, $\varepsilon(v)=\operatorname{Max}\{d(v, u) \mid \forall v \in V(G)\}$.

In 2000, the Connective Eccentric index $C^{\xi}(G)$ was defined by Gupta, Singh and Madan $[5,6]$ as follows:

$$
C^{\xi}(G)=\sum_{v \in V(G)} \frac{d_{v}}{\varepsilon(v)}
$$


where $d_{v}, \varepsilon(v)$ denote the degree and eccentric of vertex $v$ in $G$. See [7-26] for more details and other versions of Eccentric indices and Eccentric polynomials.

The goal in this paper is computing the Connective eccentric index of Circumcoronene Homologous Series of Benzenoid $H_{k}(k \geq 1)$.

\section{RESULTS AND DISCUSSION}

In this section, we compute the Connective eccentric index $C^{\xi}(G)$ of Circumcoronene Homologous Series of Benzenoid. Three first members of this Benzenoid family $\left(H_{1}=\right.$ benzene, $H_{2}=$ coronene and $H_{3}=$ circumcoronene) are shown in Figure 1 . Circumcoronene Homologous Series of Benzenoid is generated from famous molecule Benzene or cycle $C_{6}$. We encourage reader to references [18-38] to study some properties of this Benzenoid family.
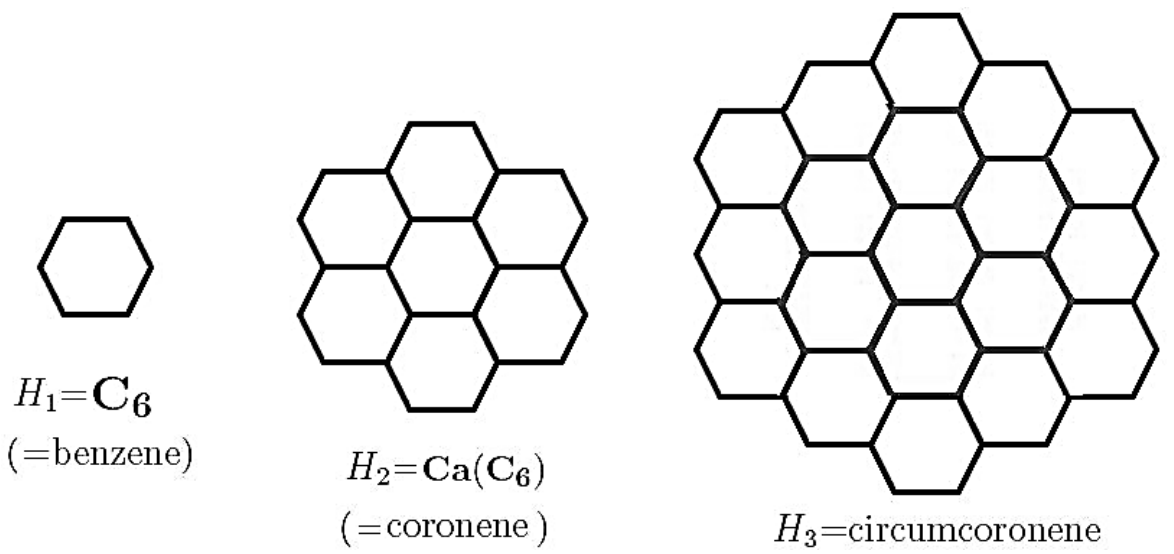

Figure 1. Three first members of Circumcoronene Homologous Series of Benzenoid: $H_{1}=$ benzene, $\mathrm{H}_{2}=$ coronene and $\mathrm{H}_{3}=$ circumcoronene [18-26].

$\forall k \in \mathrm{N}$ Circumcoronene Homologous Series of Benzenoid $H_{k}$ has $6 k^{2}$ atoms/vertices and $9 k^{2}-6 k$ bonds/edges (see Figure 2). For further study and more detail of this Benzenoid family, see the paper series [27-35]. Now, we have following theorem for this benzenoid graphs.

Theorem 1. Let $G$ be the Circumcoronene Homologous Series of Benzenoid $H_{k}(\forall k \geq$ 1). Then the Connective Eccentric index $C^{\xi}(G)$ of $H_{k}$ is equal to

$$
C^{\xi}\left(H_{k}\right)=\sum_{i=1}^{k-1}\left(\frac{9 i(4 k+4 i-1)}{2 i^{2}+(4 k-1) i+2 k^{2}-k}\right)+\frac{12 k}{4 k-1}
$$

Before prove the Theorem 1, we denote all vertices and edges of Circumcoronene Homologous Series of Benzenoid $H_{k}$, as follow adn is shown in Figure 2, ( $\mathrm{Z}_{i}$, is the cycle finite group):

$$
V\left(H_{k}\right)=\left\{\gamma_{z, j}^{i}, \beta_{z, l}^{i} \mid i=1, \ldots, k, j \in \mathrm{Z}_{i}, l \in \mathrm{Z}_{i-1}, \mathrm{z} \in \mathrm{Z}_{6}\right\}
$$


and $E\left(H_{k}\right)=\left\{\beta_{z, j}^{i} \gamma_{z, j}^{i}, \beta_{z, j}^{i} \gamma_{z, j+1}^{i}, \beta_{z, j}^{i} \gamma_{z, j+1,1}^{i-1} \mid i \in Z_{k}, j \in Z_{i}, \mathrm{Z} \in \mathrm{Z}_{6}\right\}$

Proof. By considering Circumcoronene Homologous Series of Benzenoid $G=H_{k}(\forall k \geq$ 1) as shown in Figure 2 and refer to [18-26] and using the Ring-cut Method for circumcoronene homologous series of Benzenoid, we can compute its connective eccentric index. The Ring-cut Method is a modify version of the thoroughbred Cut Method. The general form of this method is introduced in [18-26] For more study and detail information of the Cut Method see [28,31,32].

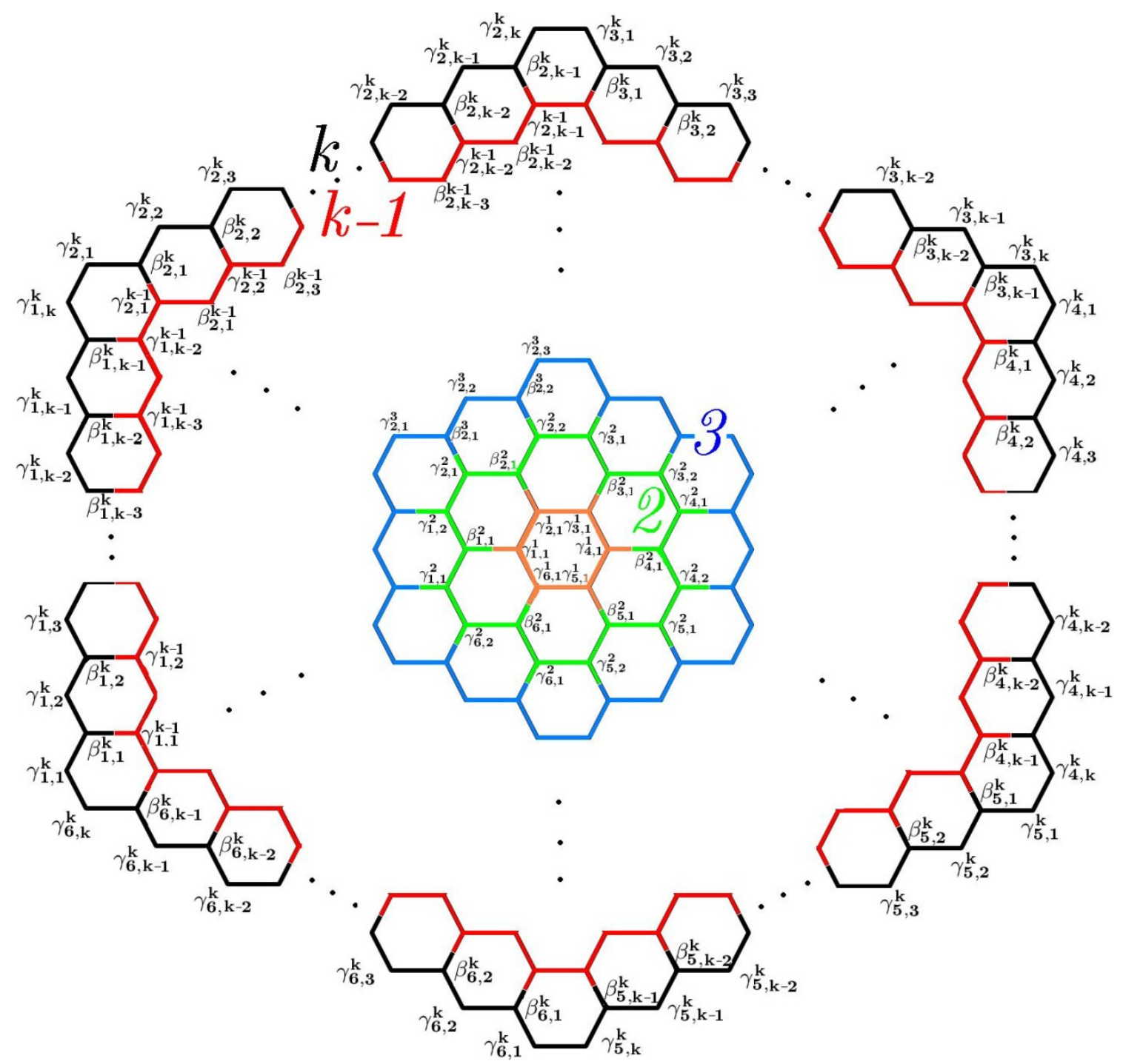

Figure 2. The general representation of Circumcoronene Homologous Series of Benzenoid $H_{k}(k \geq 1)$ [18-26].

To compute the connective eccentric index of $H_{k}$, we see that

$$
\begin{gathered}
\forall i=2, \ldots, k ; j \in \mathrm{Z}_{i-1} \& z \in \mathrm{Z}_{6}: \varepsilon\left(\beta_{z, j}^{i}\right)=2 k+2 i-2 \\
\forall i=1, \ldots, k ; j \in \mathrm{Z}_{i} \& z \in \mathrm{Z}_{6}: \varepsilon\left(\gamma_{z, j}^{i}\right)=2 k+2 i-1
\end{gathered}
$$


Also, by according to Figure 2, one can see that the vertices in general representation of molecular graph Circumcoronene Homologous Series of Benzenoid $H_{k}$ have degree two or three, such that

$$
V_{2}\left(H_{k}\right)=\left\{v \in V\left(H_{k}\right) \mid d_{v}=2\right\}=\left\{\gamma_{z, I}^{k} \mid \forall i \in Z_{i} \& z \in Z_{6}\right\}
$$

and alternatively

$$
V_{3}\left(H_{k}\right)=V\left(H_{k}\right)-V_{2}\left(H_{k}\right)
$$

$$
\begin{aligned}
& C^{\xi}\left(H_{k}\right)=\sum_{v \in V(G)} \frac{d_{v}}{\varepsilon(v)} \\
& =\sum_{\gamma_{z, j}^{k} \in V_{2}\left(H_{k}\right)} \frac{d_{\gamma_{z, j}^{k}}}{\varepsilon\left(\gamma_{z, j}^{k}\right)}+\sum_{\gamma_{z, j}^{i} \in V_{3}\left(H_{k}\right)} \frac{d_{\gamma_{z, j}^{i}}}{\varepsilon\left(\gamma_{z, j}^{i}\right)}+\sum_{\beta_{z, j}^{i} \in V_{3}\left(H_{k}\right)} \frac{d_{\beta_{z, j}^{i}}}{\varepsilon\left(\beta_{z, j}^{i}\right)} \\
& =\sum_{\substack{\gamma_{z, j}^{k} \in V_{2}\left(H_{k}\right) \\
j \in \mathbb{Z}_{k} ; z \in \mathbb{Z}_{6}}} \frac{2}{4 k-1}+\sum_{\substack{\gamma_{z, j}^{i} \in V_{3}\left(H_{k}\right) ; z \in \mathbb{Z}_{6} \\
i=1, \ldots, k-1 ; j \in \mathbb{Z}_{i}}} \frac{3}{2 k+2 i-1}+\sum_{\substack{\beta_{z, j}^{i} \in V_{3}\left(H_{k}\right) ; z \in \mathbb{Z}_{6} \\
i=2, \ldots, k, j \in \mathbb{Z}_{i-1}}} \frac{3}{2 k+2 i-2} \\
& =\sum_{z=1}^{6} \sum_{j=1}^{k}\left(\frac{2}{4 k-1}\right)+\sum_{z=1}^{6} \sum_{i=1}^{k-1} \sum_{j=1}^{i}\left(\frac{3}{2 k+2 i-1}\right)+\sum_{z=1}^{6} \sum_{i=2}^{k} \sum_{j=1}^{i-1}\left(\frac{3}{2 k+2 i-2}\right) \\
& =6 k\left(\frac{2}{4 k-1}\right)+\sum_{i=1}^{k-1}\left(\frac{3 \times 6 i}{2 k+2 i-1}\right)+\sum_{i=2}^{k}\left(\frac{3 \times 6(i-1)}{2 k+2 i-2}\right) \\
& =\frac{2 \times 6 k}{4 k-1}+\sum_{i=1}^{k-1}\left(\frac{3 \times 6 i}{2 k+2 i-1}\right)+\sum_{j=1}^{k-1}\left(\frac{3 \times 6 j}{2 k+2 j}\right) \\
& =\sum_{i=1}^{k-1}\left(\frac{18 i(2 k+2 i-1+2 k+2 i)}{2(k+i)(2 k+2 i-1)}\right)+\frac{12 k}{4 k-1}
\end{aligned}
$$

Thus $\forall k \geq 1$, the connective eccentric index of $H_{k}$ is equal to

$$
C^{\xi}\left(H_{k}\right)=\sum_{i=1}^{k-1}\left(\frac{9 i(4 k+4 i-1)}{2 i^{2}+(4 k-1) i+2 k^{2}-k}\right)+\frac{12 k}{4 k-1}
$$

and this completed the proof of Theorem 1. 


\section{CONCLUSION}

The eccentric connectivity index $\xi(G)$ is defined as $\xi(G)=\sum_{v \in V(G)} d_{v} \times \varepsilon(v)$ where $d_{v}$, $\varepsilon(v)$ denote the degree of vertex $v$ in $G$ and the largest distance between $v$ and any other vertex $u$ of $G$. In this paper, we counting the connective eccentric index $C^{\xi}(G)=\sum_{v \in V(G)} d_{v} / \varepsilon(v)$ of Circumcoronene Homologous Series of Benzenoid $H_{k}(k \geq 1)$.

\section{References}

[1] H. Wiener, J. Am. Chem. Soc. 69(1) (1947) 17-20.

[2] I. Gutman, N. Trinajstić, Chem. Phys. Lett. 17 (1972) 535-538.

[3] R. Todeschini, V. Consonni, Handbook of Molecular Descriptors, Weinheim, Wiley$\mathrm{VCH},(2000)$.

[4] V. Sharma, R. Goswami, A. K. Madan, J. Chem. Inf. Comput. Sci. 37 (1997) 273-282.

[5] S. Gupta, M. Singh, A. K. Madan, J. Mol. Graph. Model. 18 (2000) 18-25.

[6] S. Gupta, M. Singh, A. K. Madan, J. Math. Anal. Appl. 266 (2002) 259-268.

[7] A.R. Ashrafi, M. Ghorbani, M. Hemmasi, Digest. J. Nanomater. Bios. 4(3) (2009) 483486.

[8] S. Alikhani, M. A. Iranmanesh, Digest. J. Nanomater. Bios. 6(1) (2011) 253-257.

[9] I. Gutman, O. E. Polansky, Mathematical Concepts in Organic Chemistry, SpringerVerlag, New York, (1986).

[10] M. A. Johnson, G. M. Maggiora, Concepts and Applications of Molecular Similarity, Wiley Interscience, New York, (1990).

[11] M. Ghorbani, M. Ghazi, Digest. J. Nanomater. Bios. 5(4) (2010) 1107-1111.

[12] V. Kumar, S. Sardana, A. K. Madan, J. Mol. Model. 10 (2004) 399-407.

[13] M. Fischermann, A. Homann, D. Rautenbach, L. A. Szekely, L. Volkmann, Discrete Appl. Math. 122 (2002) 127-137.

[14] S. Sardana, A. K. Madan, MATCH Commun. Math. Comput. Chem. 43 (2001) 85-89.

[15] A. R. Ashrafi, M. Ghorbani, M. Jalali, Optoelectron. Adv. Mater.-Rapid Comm. 3 (2009) 823-826.

[16] H. Dureja, A. K. Madan, Med. Chem. Res. 16 (2007) 331-341.

[17] Z. Yar Ahmadi, Iran. J. Math. Chem, 1(2) (2010) 105-110.

[18] M. R. Farahani. Annals of West University of Timisoara-Mathematics and Computer Science 51(2) (2013) 29-37.

[19] M. R. Farahani. Journal of Advances in Physics 2(1) (2013) 48-52.

[20] M. R. Farahani. Int. J. Chem. Model. 6(1) (2014).

[21] M. R. Farahani, Journal of Chemica Acta 2 (2013) 22-25. 
[22] M. R. Farahani, World Applied Sciences Journal 21(9) (2013) 1260-1265.

[23] M. R. Farahani, Two New Version of Zagreb Index of Circumcoronene Series of Benzenoid. Int. J. Computational Sciences \& Applications. (2013) In press.

[24] M. R. Farahani, Chemical Physics Research Journal 6(1) (2013) 27-33.

[25] M. R. Farahani, Journal of Chemica Acta 2 (2013) 26-31.

[26] M. R. Farahani, Journal of Mathematical Nanoscience 2(1) (2012) 15-20.

[27] S. Klavžar, I. Gutman, B. Mohar, J. Chem. Int Comput. Sci. 35 (1995) 590-593.

[28] V. Chepoi, S. Klavžar, Distances in benzenoid systems: Further developments. Discrete Mathematics 192 (1998) 27-39.

[29] P. Zigert, S. Klavžar, I. Gutman, ACH Models Chem. 137 (2000) 83-94.

[30] A. Soncini, E. Steiner, P. W. Fowler, R. W. A. Havenith, L. W. Jenneskens, Chem. Eur. J. 9 (2003) 2974-2981.

[31] P. E. John, P. V. Khadikar, J. Singh, J. Math. Chem. 42(1) (2007) 27-45.

[32] S. Klavžar, MATCH Commun. Math. Comput. Chem. 60 (2008) 255-274.

[33] M. R. Farahani, M. P. Vlad, Studia Univ. Babes-Bolyai, Chemia. 57(4) (2012).

[34] M. R. Farahani, J. Applied Mathe. \& Informatics. 31(3) (2013).

[35] M. R. Farahani, Int. J. Chem. Model. 6(1) (2014).

[36] M. R. Farahani, International Letters of Chemistry, Physics and Astronomy 11(1) (2014) 74-80.

[37] M. R. Farahani, International Letters of Chemistry, Physics and Astronomy 12 (2014) 56-62.

[38] M. R. Farahani, International Letters of Chemistry, Physics and Astronomy 12 (2014) 63-68. 